\title{
EFEKTIVITAS MEDIA KARTU KOSAKATA DI SLB/C ARRAHMAN JAKARTA
}

\author{
Natalina Purba ${ }^{1}$, Reni Tiar Linda Purba ${ }^{2}$, Myrnawati Crie Handini ${ }^{3}$, Elindra Yetti ${ }^{4}$ \\ Universitas HKBP Nommensen Pematangsiantar \\ Sekolah Tinggi Bibelvrow, Laguboti \\ Universitas Sari Mutiara Medan \\ Universitas Negeri Jakarta
}

\begin{abstract}
This research is to see the effectiveness of vocabulary card media in improving the speaking ability of children with intellectual disability who can train. Conducted Arrahman SLB / B-C Jakarta. This research takes place from January 2017 to January 2018. The method used in this study is action research concerning the action research model of Kurt Lewin, where one cycle activities consist of 4 components, including planning, action, observation, and reflection. This study consisted of 1 cycle consisting of 8 actions. Data analysis using action research. In the effectiveness test of vocabulary cards, it was able to increase the ability of speech for children with intellectual disability by 21.89\%. Conclusion: Vacation cards are proven effective for improving the speaking skills of children with intellectual disability who can train. Implications, teachers in using vocabulary card media should correct and repeat the child's words.
\end{abstract}

Keyword: vocabulary cards, early childhood, children with intellectual disability, action research, speaking skills

\begin{abstract}
Abstrak: Penelitian ini untuk melihat efektivitas media kartu kosakata dalam peningkatan kemampuan berbicara anak tunagrahita mampu latih. Dilakasanakan SLB/B-C Arrahman Jakarta. Penelitian ini berlangsung dari Januari 2017 sampai dengan Januari 2018. Metode yang digunakan dalam penelitian ini adalah penelitian tindakan dengan mengacu pada model penelitian tindakan dari Kurt Lewin, dimana kegiatan satu siklus terdiri atas 4 komponen, meliputi perencanaan, tindakan, pengamatan, dan refleksi. Penelitian ini terdiri atas 1 siklus yang terdiri atas 8 tindakan. Analisis data menggunakan action research. Pada uji efektivitas kartu kosakata mampu meningkatkan kemampuan berbicara anak tunagrahita sebesar $21.89 \%$. Kesimpulan kartu kosakaa terbukti efektif untuk peningkatan kemampuan berbicara anak tunagrahita mampu latih. Implikasi, guru dalam menggunakan media kartu kosakata hendaknya mengoreksi dan mengulangi ucapan anak.
\end{abstract}

Kata Kunci: kartu kosakata, anak usia dini, tunagrahita mampu latih, penelitian tindakan, kemampuan berbicara

\section{PENDAHULUAN}

White and Bradley (1969, hlm. 10) menyatakan bahwa anak tunagrahita dengan IQ rata-rata diantara 50 sampai 70 memiliki kelamahan ditiga faktor yaitu: artikulasi, berbicara dan pendengaran. Memahami kelemahan yang dihadapi anak tunagrahita maka diperlukan media yang mampu memfasilitasi kekurangan ini. Ketika mereka masuk sekolah maka mereka akan mengalami proses belajar yang sama dengan anak yang lainnya.

Ada beberapa teori yang menjadi dasar pemikiran pemanfaatan media kartu kosakata dalam pembelajaran. Teori-teori tersebut antara lain:

\footnotetext{
${ }^{1}$ Universitas HKBP Nommensen Pematangsiantar - Indonesia| Email: natalinapurba@gmail.com

2 Sekolah Tinggi Bibelvrow, Laguboti - Indonesia:| Email: renitiarlinda@yahoo.com

${ }^{3}$ Universitas Sari Mutiara Medan - Indonesia: myrnawati@gmail.com

4 Universitas Negeri Jakarta, Indonesia: elindrayetti@unj.ac.id
} 
1.1 Teori Belajar Behavioristik

Pembelajaran dengan menggunakan media kartu kosakata untuk anak tunagrahita dilandasi oleh teori behavioristik, di mana teori ini dipelopori oleh Thorndike dan Pavlov serta Skinner yang menyatakan bahwa belajar adalah tingkah laku yang dapat diamati yang disebabkan stimulus dari luar dan menekankan pada terbentuknya perilaku yang tampak sebagai hasil belajar. Sesorang dikatakan belajar ditunjukkan dari perilaku yang dapat dilihat bukan dari apa yang ada dalam pikiran anak (Gredler, 2009, hlm. 36-49).

Sedangkan Watson mendefiniskan belajar sebagai proses interaksi antara stimulus dan respon yang dimaksud harus dapat diamati (observable) dan dapat diukur) jadi walaupun mengakui adanya perubahan-perubahan mental dalam diri seseorang selama proses belajar namun menjadi faktor yang tidak diperhitungkan karena tidak dapat diamati (Gredler, 2009, hlm. 37).

Menurut Slavin, belajar merupakan akibat adanya interaksi antara stimulus dan repon, seseorang telah dianggap belajar sesuatu jika dapat menungjukkan perubahan perilaku (Slavin, 2006, hlm. 134-140). Faktor yang juga dianggap penting oleh aliran behavioristik adalah faktor penguatan (reinforcement). Bila penguatan ditambahkan (positive reinforcement) maka respon akan semakin kuat. Begitu pula bila penguatan dikurangi atau dihilangkan (negative reinforcement) maka repon juga semakin berkurang. Berdasarkan pendangan beberapa ahli penganut aliran behavioristik menunjukkan bahwa perlu dilakukan pengukuran respon anak terhadap media pembelajaran yang telah digunakan selama proses belajar mengajar.

\section{2. Konstruktivisme Kognitif}

Konstruktivisme kognitif didasarkan pengembangan yang dibuat oleh ahli psikologi perkembangan Swiss, Piaget.
Teori Piaget ini mengandung dua unsur pokok yaitu: umur dan tahap perkembangan. Melalui dua unsur ini bisa diprediksi apa yang bisa dan tidak bisa dilakukan oleh seorang anak berdasarkan umurnya, serta teori perkembangan yang menjelaskan bagaimana seorang anak membangun kemampuan kognitifnya.

Menurut perkembangan kognitif Piaget, manusia tidak dapat langsung dimengerti dan bisa digunakan. Manusia akan mengkonstruksikan pengetahuannya. Manusia akan membentuk pengetahuan berdasarkan pengalamannya. Pengelaman ini memungkinkan membentuk skemamental model dalam pikiran kita. Skema ini berkembangan semakin luas dan semakin canggih melalui dua proses yang saling melengkapi yaitu asimilasi dan akomodasi (Gredler, 2009, hlm. 275). Berdasarkan teori Paiget ini, ada dua hal yang penting berkenan dengan proses pembelajaran yaitu: belajar adalah suatu proses aktif dan menyeluruh, autentik dan nyata

\subsection{Teori Dale Cone Experience}

$$
\text { Pemerolehan pengetahuan, }
$$
perubahan sikap dan keterampilan dapat terjadi karena interaksi antara pengalaman baru dengan pengalaman yang dialami sebelumnya. Menurut Bruner ada 3 tingkatan utama modus belajar yaitu pengalaman langsung (enactive). pengalaman gambar/piktoral (iconic) dan pengalaman abstrak (symbolic) (Master: 2013). Tingkatan pengalaman pemerolehan hasil belajar seperti ini digambarkan oleh Dale sebagai suatu proses berbicara (Kustandi \& sujipto: 2011, hlm. 10). Materi yang ingin disampaikan dan yang diinginkan anak agar dapat menguasai disebut sebagai pesan.

Proses pembelajaran dapat berhasil dengan baik bila anak diajak untuk memanfaatkan semua alat inderanya. Guru berupaya untuk menampilkan rangsangan yang dapat diproses dengan inderanya. Semakin 
banyak alat indera yang digunakan untuk menerima dan mengolah infomasi, semakin besar kemungkinan informasi tersebut dan dipahami serta dipertahankan dalam ingatan.

$\begin{array}{lll}\text { Dale } & \begin{array}{l}\text { memandang } \\ \text { mediam }\end{array} & \begin{array}{l}\text { bahwa nilai } \\ \text { pembelajaran }\end{array}\end{array}$
diklasifikasikan berdasarkan nilai pengalaman. Menurut Dale, pengalaman itu mempunyai dua tingkatan. Tingkat pengalaman yang paling tinggi nilainya adalah pengalaman yang paling kongkrit, sedangkan yang paling bawah adalah yang paling abstrak.

Jika dilihat dari kerucut pengalaman Dale, pembelajaran mennggunakan media kartu kosakata ada dibeberapa wilayah pengalaman belajar. Materi pembelajaran kartu kosakata utamanya berisi gambar dan kata. Selain itu dengan desain Assure dapat dengan mudah menerapkan dengan anak yang memiliki kebutuhan khusus dalam hal ini anak tunagrahita.

PECS telah membantu anak dengan kebutuhan khusus terutama anakanak dengan hambatan intelektual atau tunagrahita (McDonald et.al, 2015). Dengan menggunakan benda atau objek yang disukai untuk merangsang anak berbicara, dapat dimulai dengan media kartu kosakata dengan objek yang disukai (reinforcers), sehingga membuat anak termotivasi untuk belajar berbicara.

Akhir dari proses pembelajaran adalah hasil belajar. Berdasarkan pengalaman belajar sebagai mana digambarkan Dale maka tingkat keberhasilan anak jika anak dapat belajar dengan mendengarkan melihat meraba dan mengevaluasi. Untuk mencapai tingkat respon hasil belajar sebagai mana yang dikamaksud maka diperlukan pembelajaran dengan bantuan media. Terakhir, penelitian ini untuk mencari jawaban atas pertanyaan Bagaimana efektivitas media kartu kosakata dalam meningkatkan kemampuan berbicara anak tunagrahita mampu latih?

\section{METODOLOGI PENELITIAN}

Uji efektivitas media pembelajaran dalam penelitian ini tidak hanya diperoleh dari tanggapan penguna saat uji coba lapangan tetap juga diketahui hasilnya dengan menggunakan action research yang menggunakan model Kurt Lewin.

Lewin mengatakan "there is nothing so practical as a good theory" (Kolb, 1984) model Lewin menjadi pilihan karena memberi panduan praktis bagi guru untuk melakukan apa yang harus dilakukan dalam situasi pendidikan tertentu dan dapat digunakan untuk intervensi pedagogis. Berikut ini adalah bagan 1 dari model Kurt Lewin.

Pada penelitian tindakan ini peneliti mengacu pada prosedur penelitian Model Kurt Lewin, yang terdiri dari empat langkah yaitu perencanaan,tindakan, observasi dan refleksi (Kolb:1984). Berikut ini paparan hasil pelaksanaan uji efektivitas melalui action research menggunakan media kartu kosakata.

1) Perhitungan Hipotesis Non Parametrik Dengan Menggunakan Model Wilcoxon

Untuk data nilai pra penelitian dan pasca penelitian yang diperoleh pada saat uji coba lapangan dianalisis dengan menggunakan uji peringkat bertanda Wilcoxon atau dalam kasus berpasangan tersebut juga uji Wilcoxon bagi pengamatan berpasangan. Wilcoxon menggunakan uji two related sample yang artinya melakukan juga uji t.

2.1 Program Peningkatkan Kemampuan Berbicara

\section{a) tindakan}

Pada awal penelitian, dilakukan asesmen awal yang bertujuan untuk mengetahui kondisi awal kemampuan berbicara anak. Pada asesmen awal ini data kuantitatif diperoleh dengan menggunakan rating scale. Hasil observasi, selanjutnya dianalisis sesuai dengan kondisi awal yang dimiliki. Ada satu dimensi yang diobservasi, yaitu 
berbicara terdiri dari lima indikator yaitu: a) tekanan/Intonasi, b) tata bahasa, c) penguasaan kosakata, c) kelancaran, dan e) pemahaman.

\section{c) Observasi}

Tahap observasi dilakukan untuk mengetahui sejauh mana intervensi tindakan yang telah memberikan dampak

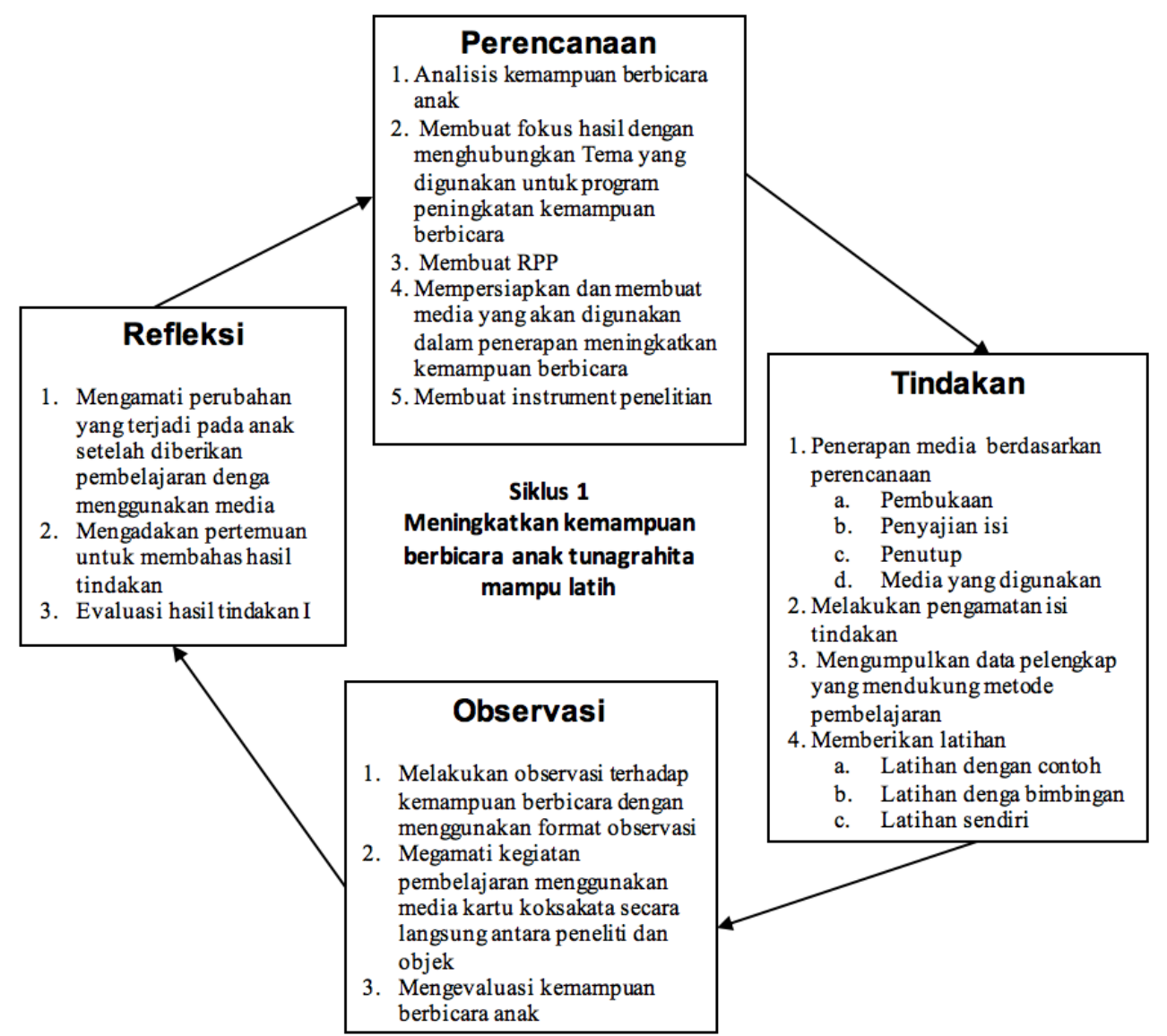

\section{b) Pelaksanaan Tindakan}

Level 1: Bermain dengan gambar

Dilkasanakan dua kali pertemuan yaitu Senin - Selasa, 25-26 Oktober 2017

Durasi setiap pertemuan 120 Menit

Level 2: Mencari kosakata berdasarkan gambarnya yuk

Dilasanakan dua kali pertemuan yaitu

Kamis - Jumat, 28-29 Oktober 2017

Durasi setiap pertemuan 120 Menit

Level 3: Mari buat kalimat sederhana

Dilaksanakan dua kali pertemuan yaitu

Senin- Selasa, 30-31 Oktober 2017

Durasi setiap pertemuan 120 Menit

Level 4: Mari bercerita dengan gambar

Diklasanakan dua kali pertemuan yaitu

Kamis-Jumat, 2-3 November 2017

Durasi setiap pertemuan 120 Menit peningkatan yang diharapkan dalam penelitian tindakan, atas dasar observasi ternyata secara umum pendekatan model Gestalt dalam meningkatkan kemampuan berbicara anak sangat efektif.

Pelaksanaannya menekankan pada pembelajaran secara bertahap yaitu peneliti dan kolaborator menekankan pada sub tema (1) ayahku, (2) ibuku (3) aku dan sudaraku (4) kegiatanku bersama keluargaku. Indikator yang digunakan adalah a) tekanan/Intonasi, b) tata bahasa, c) penguasaan kosakata, c) kelancaran, dan e) pemahaman.

Hasil dari penelitian ini diperoleh menolak $\mathrm{H}_{0}$ dan menerima $\mathrm{H}_{1}$ menyatakan tidak terdapat penolakan perbedaan antara pra penelitian dan pasca 
penelitian artinya terdapat perbedaan antara pra penelitan dan pasca penelitian.

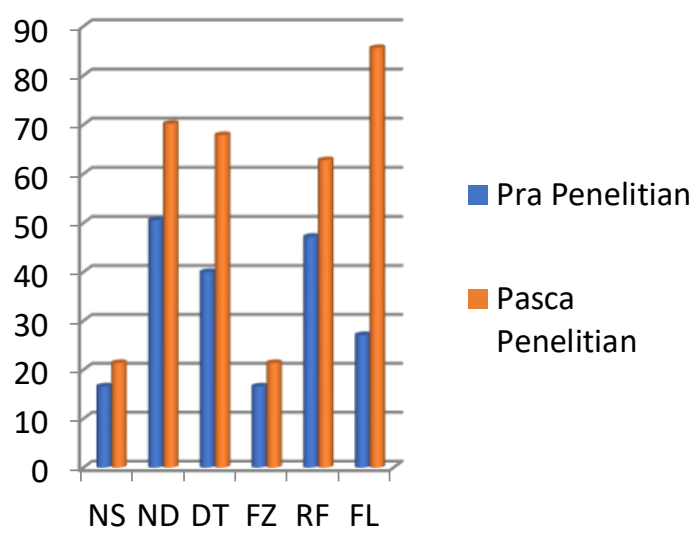

Grafik 4.2 Pra dan Pasca Penelitan

Berdasarkan grafik di atas, semua anak mengalami peningkatan. Namun yang signifikan peningkatannya adalah 4 orang anak, dengan demikian penelitian ini mengalami peningkatan. Berdasarkan pengamatan, tujuan dan target pencapaian dari penelitian tindakan ini sudah mencapai target, yaitu secara umum ratarata anak sudah menunjukkan peningkatan dalam kemampuan kemampuan berbicara anak tunagrahita mampu latih, dengan model belajar global.

Secara presentasi dapat di katakan telah terjadi peningkatan pada awal penelitian atau pra penelitian dari $33.01 \%$ meningkat menjadi $54.9 \%$ artinya telah terjadi peningkatan sebesar $21.89 \%$. Anak tunagrahita mampu latih, dengan jumlah 2 orang dalam kelas di SDLB/C Asih Budi dan 6 orang di SLB/C Arrahman, jumlah keseluruhan 8 anak, IQ di bawah 60, Pendengaran terganggu, berkomunikasi/berbicara terganggu, artikulasi tidak jelas. Memilih metode global sebagai metode untuk mengajarkan media kartu kosakata (K2) untuk meningkatkan kemampuan berbicara anak.

\section{d) Refleksi}

Berdasarkan refleksi antara peneliti dan kolaborator terdapat beberapa hal terkait dengan pembelajaran model belajar modifikasi perilaku pada kegiatan yang perlu diperhatikan:

1. Setiap anak adalah unik, sehingga guru dan peneliti harus menggunakan berbagai cara agar anak tetap fokus pada pembelajaran juga harus membagi dan memberikan perhatian yang merata pada setiap anak.

2. Fokus perhatian dan motivasi sudah optimal

3. Keterlibatan anak untuk memfokuskan perhatian sudah optimal karena anak sudah akrab melalui penjajakan sebelum penelitian berlangsung.

4. Anak sangat senang ketika bernyanyi bersama keceriaan bertambah ketika anak diberi waktu untuk bermain.

Dalam kegiatan penyajian kependidikan, pendekatan yang peneliti pilih ternyata mampu memotivasi anak untuk mau bertanya, dan menjawab serta melakukan semua instruksi peneliti. Kartu kosakata yang dikembangkan oleh peneliti dengan menggunakan metode global terbukti yang cocok untuk diterapkan pada anak tunagrahita mampu latih. Kartu kosakata ini dengan menggunakan metode global, mampu mendorong semangat dan antusias belajar anak lebih mandiri dan maksimal. Ini terbukti dari hasil observasi bahwa anak tidak kaku menerima pembelajaran, terjadi keterkaitan dan kebersamaan selama proses pembelajaran berlangsung sampai akhir pembelajaran.

\section{HASIL PENELITIAN DAN PEMBAHASAN}

Media pemelajaran bisa digunakakan kapan dan di mana saja, tidak ada ketentuan kapan media harus digunakan. Tetapi sangat disarankan para guru untuk memilih dan menggunakan media pembelajaran dengan tepat. Penggunaan media pembelajaran yang tidak tepat kan menyebabkan tidak tercapainya tujuan pembelajaran. Termasuk pembelajaran untuk meningkatkan kemampuan berbicara di 
SLB/BC Arrahman Jakarta sebagai suatu kemampuan yang harus dimiliki anak tunagrahita mampu latih maka penggunaan media kartu kosakata menjadi sangat penting.

Metode Picture Exchange

Communication System (PECS) dapat meningkatkan kemampuan berbicara untuk individu yang memiliki kesulitan dalam berbicara. Dikembangkan pada tahun 1985 oleh Andrew Bondy dan Lori Frost, PECS awalnya digunakan untuk anak usia prasekolah dengan ASD (autism spectrum disorders) dan gangguan komunikasi sosial lainnya (Kai-Chien Tien, 2008, hlm. 61-76). Sistem Komunikasi Pertukaran Gambar (PECS) sangat efektif untuk meningkatkan komunikasi fungsional keterampilan individu dengan spektrum gangguan autisme. Akhirnya PECS penjadi sebuah pilihan yang menantang digunakan di dalam kelas terutama kelas anak tunagrahita.

Light (2014) dua puluh lima tahun yang lalu, terus memberikan kerangka kerja yang berguna untuk era komunikasi yang baru ini. Terlepas dari perubahan dramatis di lapangan tujuan intervensi AAC tidak berubah. Intervensi AAC harus mengatasi pengembangan keterampilan komunikasi fungsional yang memadai untuk mendukung individu dengan kebutuhan komunikasi yang kompleks dalam mengembangkan, membangun kembali, atau mempertahankan komunikasi. Kemampuan untuk mengungkapkan kebutuhan dan keinginan, mengembangkan kedekatan sosial, bertukar informasi, dan berpartisipasi dalam rutinitas sosial sesuai kebutuhan.

Hal ini didukung hasil temuan yang dilakukan Memisevic dan Hadzic (2013) mengungkapkan bahwa anak-anak dengan hambatan intelektual memiliki risiko lebih tinggi dalam mengembangkan kemampuan berbicaranya. Anak dengan hambatan intelektual atau yang lebih dikenal denan tunagrahita memiliki keterbatasan yaitu gangguan bicara dan bahasa, dibandingkan dengan anak-anak pada umumnya.

Penelitian kemampuan bahasa anak dengan downsyndrom masih sangat jarang, salah satu penelitian yang dilakukan Shnitzer-Meirovich dan kawankawan menemukan bahwa individuals with non-specific intellectual disability (NSID) terutama downsyndrom akan memiliki keterlambatan dalam perkembangan bahasanya sehingga dibutuhkan intervensi sedini mugkin (Shnitzer-Meirovich et al, 2017, hlm. 252267). Seiring bertambahnya usia anak akan mengalami kesulitan untuk untuk meningkatkan kemampuan berbicara. Mengingat di dalam kelas ada tiga anak dengan indikasi downsyndrome.

Bagi anak yang kemampuan berbicaranya tidak berkembang dengan baik seperti $\mathrm{Hd}$ dapat mengandalkan bahasa tubuh seperti menunjuk, mencapai benda yang diinginkan, memandang mata, dan ekspresi wajah lainnya, dan terutama untuk perilaku.

Kartu kosakata sebagai media dalam proses pembelajaran memiliki keistimewaan yang tidak dimiliki oleh media lain, yaitu: 1) sebagai media yang efektif untuk menumbuh kembangkan minat anak dalam pembelajaran, 2) menjadikan anak terlibat dan berpartisipasi aktif dalam proses pembelajaran, 3) anak yang menggunakan media kartu kosakata lebih cepat mengingat gambar karena karakter dan warna gambar yang menarik.

Anak sangat tertarik dengan gambar yang memiliki warna menarik hal ini didukung oleh penelitian yang dilakukan oleh Nakamura (2015) yang menemukan anak sangat antusias dalam belajar dengan menggunakan buku bergambar, walaupun menggunakan gambar yang sama dengan cerita yang berbeda anak tidak akan bosan. Ini sesuai dengan hasil penelitian Purba dan kawankawan bahwa warna memiliki peran yang sangat penting dalam kartu kosakata 
(Purba, Handini, \& Yetti, 2018). Penelitian inipun didukung oleh Houglum dan kawan-kawan bahwa penggunaan kartu kosakata untuk ASD sangat efektif (Houglum et al, 2013:, hlm. 11-37).

Peneliti berpijak pada Gastalt theory tentang bentuk visual yang di dasari oleh pemikiran Chr. von Ehrenfels (Chang et al, 2002), kemudian dikembangkan oleh Max Wertheimer, Wolfgang Kohler, Kurt Koffka, tentang gerak yang dirasakan tanpa melihat objek bergerak, dimana individu akan melihat sesuatu secara keseluruhan kemudian akan bergeser ke item yang menurut individu menarik. Menurut Schichida (2010, hlm. 35) imaji yang sangat kaya selalu mengalir di belahan otak kanan. Imaji akan menjadi kekuatan ketika gelombang otak turun di bahwah $10 \mathrm{~Hz}$ di mana hormone yang memfasilitasi daya guna kesadaran otak kanan dilepaskan, ketika anak berfikir maka jiwa, emosi dan fisiologi diubah menjadi image, yang berada dibawah kesadaran otak kanan.

Belajar dengan kartu kosakata otomatis menggunakan mata sebagai alat indra yang digunakan maka mata memiliki peran penting dalam proses pembelajaran ini (LaValle, hlm. 2012). Proses pembelajaran dapat berhasil dengan baik bila anak diajak untuk memanfaatkan semua alat inderanya. Guru berupaya untuk menampilkan rangsangan yang dapat diproses dengan inderanya. Semakin banyak alat indera yang digunakan untuk menerima dan mengolah infomasi, semakin besar kemungkinan informasi tersebut dan dipahami serta dipertahankan dalam ingatan.

Keberhasilan sebuah tidakan di dalam kelas sangat tergantung pada kemampuan guru dalam memberikan stimulasi. Kemampuan berbicara menuntut guru memiliki suara yang jelas tidak ada kecatatan dalam bunyi hasil penelitian ini menujukkan bahwa guru dengan vokal yang jelas dan tegas menentukan keberhasilan penelitian ini.
Ada beberapa hal yang harus diperhatikan guru pertama mengucapkan dengan lantang dimana guru meminta anak mengulang kata yang diucapkan sambil mengoreksi kesalahan pengucapan anak, kedua adalah pengulangan di mana anak diminta untuk mengulang setelah pengucapan yang benar.

O’Bannon dan Puckett (2010, hlm.

52) meyatakan bahwa setiap anak berkebutuhan khusus mampu mengakses teknologi. Artinya guru harus mampu memberikan rangsangan terhadap anak berkebutuhan khusus agar dapat beradaptasi terhadap media yang telah disediakan guru. Oleh sebab itu guru harus memperhatikan material yang digunakan untuk media tersebut.

Beberapa strategi pengajaran untuk anak tunagrahita mampu latih adalah pengajaran terstruktur, guru atau orang dewasa menggunakan kata-kata dan frasa yang lebih sedikit atau sederhana dan harus dibantu dengan media untuk meningkatkan kemampuan berbicaranya. Hal ini senada dengan hasil temuan Irvin dan kawan-kawan bahwa untuk meningkatkan kemampuan berbicara anak dengan indikasi ASD perlu memperhatikan kesederhanaan bahasa (Irvin et al: 2013, hlm. 947-955).

\section{KESIMPULAN}

Media Kartu kosakata efektif untuk meningkatkan kemampuan berbicara anak tunagrahita mampu latih.

Adapun implikasinya adalah Penerapan media kartu kosakata bagi anak tunagrahita mampu latih terbukti efektif untuk meningkatkan kemampuan berbicara anak tunagrahita mampu latih. Selama pembelajaran berlangsung yang paling penting dan utama yang harus diperhatikan guru dalam menggunakan media kartu kosakata adalah repeating dan correcting, pengulangan dan koreksi. Ini penting agar tidak ada kesalahan pengucapan. 
DAFTAR PUSTAKA

Chang, D., Dooley, L., \& Tuovinen, J. E. (2002, July). Gestalt theory in visual screen design: a new look at an old subject. In Proceedings of the Seventh world conference on computers in education conference on Computers in education: Australian topics-Volume 8 (pp. 512). Australian Computer Society, Inc..

Purba, N., Handini, M. C. H., \& Yetti, E. (2018). Development of Media Vocabulary Cards to Improve the Speech Competence of Children with Intellectual Disabilities, 6 .

Gredler, M. E. (2009). Learning and instruction: Theory into practice. Prentice Hall.

Houglum, R., McLaughlin, T. F., Weber, K., Neyman, J., \& Gould, C. (2013). The effectiveness of direct instruction flashcards with guided practice activities to instruct two elementary students diagnosed with autism spectrum disorder and delays in pre-academics and communication. International Journal of Basic and Applied Science, 2(1), 11-38.

Kolb, D. A. (1984). Experience as the source of learning and development. Upper Sadle River: Prentice Hall.

Tien, K. C. (2008). Effectiveness of the Picture Exchange Communication System as a functional communication intervention for individuals with autism spectrum disorders: A practice-based research synthesis. Education and Training in Developmental Disabilities, 6176.

Kustandi, C., \& Sutjipto, B. (2011). Media pembelajaran manual dan digital. Bogor: Ghalia Indonesia.

LaValle, S. M. (2016). Virtual Reality, University of Illinois:, 120-145, http://vr.cs.uiuc.edu/For a more interesting discussion, read on $\mathrm{C}$.
Neil Macrae et al, Eye Gaze and Person Perception, Psychological Science, Vol. 13, No. 5, September 2012

Light, J., \& McNaughton, D. (2014). Communicative competence for individuals who require augmentative and alternative communication: A new definition for a new era of communication?.

Memisevic, H., \&Hadzic, S.Speech and Language Disorders in Children with Intellectual Disability in Bosnia and Herzegovina, Vol. 24, No. 2, 2013; doi 10.5463/DCID.v24i2.214, www.dcidj.org

Master, K. (2013) Edgar Dale's Pyramid of Learning in medical education: A literature review. Medical Teacher, 35

(11), https://doi.org/10.3109/0142159X. 2013.800636

McDonald, M. E., Battaglia, D., \& Keane, M. (2015) Using Fixed IntervalBased Prompting to Increase Student's Initiation of the Picture Exchange Communication System, Behavioral Development Bulletin, Vol. 20, No. 2, 265-275, 19420722/15/, http://dx.doi.org/10.1037/h0101315 Nakamura, M. (2015) The Three-Stage Literacy Program: A Picture Book Based Unit for Young Children, THE LANGUAGE TEACHER 39.6, November / December 2015. (jaltpublications.org/tlt)

O'Bannon, B. W.,\&Puckett, K. (2010) Preparing to Use Technology. A Practical Guide to Curriculum Integration. $2^{\text {nd }}$ ed. (New York: Pearson) h.52

Purba, N., Handini, M. C. H., \& Yetti, E. (2018). Development of Media Vocabulary Cards to Improve the Speech Competence of Children with Intellectual Disabilities, 6 .

Schichida, M. (2010) The Mystery of The Right Brain Mengungkapkan 
Misteri Otak Kanan Untuk Membuat Anak Jadi Jenius, (Jakarta: Gramedia) h. 35. For a more interesting discussion, read on Johan Wagemans, Historical and Conceptual Background: Gestalt Theory, USA: Oxford University Press.

Slavin, R. E. (2006) Educational Psychology, Theory And Practice, $8^{\text {th }} E d$. (Boston: Pearson Education, Inc), hh.134-140.

Shnitzer-Meirovich, Shlomit., et al, (2017) Comprehension of Verbal and Visual Metaphors among Individuals with Intellectual Disability with and without Down Syndrome, Education and Training in Autism and Developmental Disabilities,, 52(3), 252-267

White, H. S. L\&Bradley, D. P. (1969) Communication Problems in Mental Retardation (New York: Harper \& Row, Publisher, 1969), h. 10 